\title{
Qualitative evaluation of microfibrillated cellulose using the crill method and some aspects of microscopy
}

\author{
Sinke H. Osong · Sven Norgren • Per Engstrand • Mathias Lundberg • \\ Mehedi Reza $\cdot$ Vuorinen Tapani
}

Received: 8 February 2016/ Accepted: 6 September 2016/Published online: 9 September 2016

(C) The Author(s) 2016. This article is published with open access at Springerlink.com

\begin{abstract}
It has been a challenge to develop rapid online characterisation techniques for nanocellulose given the fibrillar structure of the nanoparticles. The crill optical analyser uses optical response signals in the infrared (IR) and ultraviolet (UV) wavelength ranges to evaluate the particle size properties of micro/nanofibrillar cellulosic materials. In this work, the crill analyser was used to measure the projected areas of UV and IR light sources by measuring the light blocked by nanocellulosic particles. This work uses the crill methodology as a new, simplified technique to characterise the particle size distribution of nanocellulosic material based on chemi-thermomechanical pulp (CTMP), thermomechanical pulp (TMP), and sulphite pulp (SP). In the first part, hydrogen peroxide pretreatment of CTMP and TMP in a wing mill refiner followed by high-pressure homogenisation to produce microfibrillated cellulose
\end{abstract}

S. H. Osong $(\bowtie) \cdot S$. Norgren $\cdot$ P. Engstrand

Department of Chemical Engineering, Faculty of Science,

Technology, and Media, Mid Sweden University,

85170 Sundsvall, Sweden

e-mail: henshaw.sinke@miun.se;

sinkehenshaw@yahoo.com

M. Lundberg

PulpEye AB, Box 279, 89126 Örnsköldsvik, Sweden

M. Reza · V. Tapani

Department of Forest Products Technology, Aalto

University School of Science and Technology,

P.O. Box 16100, 00076 Aalto, Finland
(MFC) was evaluated using the crill method. In the second part, TEMPO oxidation of CTMP and SP combined with high-shear homogenisation to produce MFC was studied using the crill method. With $4 \%$ hydrogen peroxide pretreatment, the crill values of the unhomogenised samples were 218 and 214 for the TMP and CTMP, respectively, improving to 234 and 229 after 18 homogenisation passes. The results of the TEMPO method indicated that, for the $5 \mathrm{mmol} \mathrm{NaClO}$ SP-MFC, the crill value was 108 units at $0 \mathrm{~min}$ and 355 units after 90 min of treatment, a $228 \%$ improvement. The CTMP and TMP fibres and the MFC were freeze dried and fibrillar structure of the fibres and microfibrils was visualised using scanning electron and transmission electron microscopy.

Keywords Crill $\cdot$ Nanocellulose $\cdot$ Microfibrillated cellulose $\cdot$ Hydrogen peroxide $\cdot$ TEMPO $\cdot$ SEM

\section{Introduction}

The history of MFC started in the early 1980s, when cellulose fibres were mechanically treated in highpressure homogenisers to produce fibrillar particles in work initiated by Turbak et al. (1983) and Herrick et al. (1983). There has been debate about the terminology and nomenclature for nanocellulose, which many researchers refer to as cellulose microfibril (CMF), microfibrillated cellulose (MFC), cellulose 
nanofibril (CNF), or nanofibrillated cellulose (NFC) (Hubbe et al. 2008, Siró and Plackett 2010, Eichhorn et al. 2010, Klemm et al. 2011, Moon et al. 2011, Abdul Khalil et al. 2012). In this work, we have chosen to use the term MFC. Several methods have been used to disrupt cellulosic biomass to produce nanocellulose, including conventional mechanical treatment (Turbak et al. 1983) as well as chemical (Saito et al. 2006, 2007) and enzymatic (Pääkkö et al. 2007) methods. The application of microfibrillated cellulose in pulp and paper products is gaining importance given the high strength-to-weight ratio, renewability, and environmental friendliness of this newly engineered biomaterial. Some of the special properties of woodbased nanocellulose include renewability, high strength and stiffness, low density, biodegradability, low thermal expansion, and a high aspect ratio (Charreau et al. 2013).

It is currently well known that the morphology and fibrillation state of MFC differ considerably depending on the raw material used. In this work, we explore the use of mechanical pulps such as chemi-thermomechanical pulp (CTMP) and thermomechanical pulp (TMP) as potential raw materials for producing nanocellulosic materials. Other researchers (Spence et al. 2010; Lahtinen et al. 2014) have attested that it is very difficult to produce well-individualised fibrils from mechanical pulps using a solely mechanical treatment approach. However, by combining both chemical pretreatment and the main mechanical treatment, it is possible to improve the fibrillation efficiency of MFC production. Recently, Brodin and Eriksen (2014) reported the production of very-wellindividualised MFC from TMP, with a view to using the material as a paper strength additive. They used both sulphonation and carboxymethylation pretreatment strategies combined with homogenisation to produce MFC. The sulphonation approach was implemented so as to induce acidic groups and to swell and soften the fibres. They reported that this sulphonation approach did not improve the fibrillation efficiency to any great extent, suggesting that the level of sulphonation was too low to realise a reasonable improvement in fibrillation. The poor fibrillation of the sulphonation approach was supported by light microscopy images, which showed that the MFC comprised residual fibres, fines, and fibril fragments.

The mechanical processing of cellulosic nanomaterials is very energy intensive. Pääkkö et al. (2007) used enzymatic pretreatment combined with mechanical homogenisation to produce MFC. A more efficient and promising method used to extract fibrils from fibres is the 2,2,6,6-tetra-methyl-piperidinyl-1-oxy (TEMPO)-mediated oxidation method described by Saito et al. (2006, 2007). Isogai (2013) reported that the energy intensity of nanocellulosic material processing could be reduced by surface chemistry pretreatment of the cellulosic fibres before mechanical fibrillation. One of the most reliable surface chemistry pretreatments in terms of energy and fibrillation efficiency is the TEMPO-mediated oxidation method. In this method, the C-6 primary hydroxyl groups on the surface structure of cellulose are selectively oxidised into C-6 carboxylate and some aldehyde groups (Saito et al. 2006). There are two basic TEMPO-mediated oxidation systems: TEMPO/ $\mathrm{NaBr} / \mathrm{NaClO}$, which works well at $\mathrm{pH} 10$, and TEMPO/NaClO/NaClO${ }_{2}$, which works well at $\mathrm{pH}$ 4-7 (Isogai et al. 2011a, b).

Hyll (2015) reported that several measurement techniques in relation to size and shape take into account the particle length, width, area, and equivalent diameter. She also revealed that many fibrillar particles could be characterised using optical, chemical, or rheological measurements. Most optical devices are well suited for characterising large particles such as fibres, as the detectors are usually large enough to cover the entire fibre (Hyll 2015). She also pointed out their larger detectors limit these optical devices to using lower magnification, making it extremely difficult to detect and evaluate smaller particles in the nanoscale range. MFC and fines seem to be difficult to evaluate quantitatively using optical devices, as most of the micro- and nanoparticles can go undetected and unevaluated. However, in this work we used the crill methodology as a qualitative technique for evaluating at least the fibrillation efficiency after fibre treatment in mechanical equipment.

One could consider microfibrillated cellulose as comprising very heterogeneous cellulose micro-particles, as it consists of fibres, fibrils, fines, fibre fragments, and fibril bundles. In most published work on nanocellulose, the overall goal has been to characterise the material in terms of fibril width, and this has been successfully done using microscopy techniques such as AFM, SEM, and TEM; however, these methods are time consuming and very costly. Recently, interest has been growing in alternative 
techniques for characterising MFC and in cheaper production concepts that could lower the processing cost and make the material economically feasible. One of the most promising characterisation methods is the crill method, while a promising new production method combines fractionation with mechanical homogenisation. The crill measurement technique is based on the optical responses of a micro/nanoparticle suspension to two wavelengths of light, ultraviolet (UV) and infrared (IR). The UV light conveys information on both fibres and crill, while IR conveys information only on fibres. The technique provides reliable estimates of the particle size of micro/nanofibres. The crill method can be used at the pulp mills for measuring hairy fibre particles and controlling fines content during refining. It is a robust, fast, and reliable method for assessing tiny fibrils. The method creates opportunities for qualitatively evaluating particle size measurement of nanocellulose, including TEMPOoxidised nanocellulose, hydrogen peroxide-based nanocellulose and other nanocellulose qualities. However, as the measurement technique is still under development, it can only measure fibrils at the submicron scale.

The main objective of this work is to use the crill methodology as a new simplified characterisation technique to evaluate the particle size of nanocellulosic material based on mechanical pulps (CTMP and TMP) and sulphite pulp (SP). The first section of this work evaluates, using the crill method, the hydrogen peroxide $\left(\mathrm{H}_{2} \mathrm{O}_{2}\right)$ pretreatment of CTMP and TMP in a wing mill refiner followed by high-pressure homogenisation to produce MFC. The second section uses the crill method to study the TEMPO oxidation of CTMP and SP combined with high-shear homogenisation to produce MFC. Again, it is worth noting that the intention of this work is to show the use of the crill method as a characterisation tool for nanocellulosic materials.

\section{Materials and methods}

Pulps for section 1

\section{Thermo-mechanical pulp (TMP)}

The TMP sample used here was obtained from the SCA pulp mill at Örtviken, Sundsvall, Sweden; it had a
Canadian Standard Freeness (CSF) value of approximately $65 \mathrm{~mL}$ and a dry solid content of $34 \%$. The wood type used was fresh Norway spruce (Picea abies).

\section{Chemi-thermomechanical pulp (CTMP)}

The CTMP sample used in this investigation was obtained from the SCA Östrand pulp mill, Sundsvall, Sweden. The wood material used was solely neverdried Norway spruce (Picea abies) with a high CSF value of approximately $619 \mathrm{~mL}$.

\section{Pulp washing}

A $1 \%$ diethylenetriamine penta-acetic acid (DTPA) solution was used to wash $150 \mathrm{~g}$ of o.d. pulp of approximately $5 \%$ consistency. The pulp slurry was placed in a plastic bag and sealed. The bag was then put into a hot water bath at approximately $70{ }^{\circ} \mathrm{C}$ for $1 \mathrm{~h}$ for the reaction to be effective. After that, the DTPA solution was washed out with distilled water using a Buchner funnel. A pulp dry solids content of approximately $18 \%$ was achieved for all the samples, which were stored in a refrigerator at $4{ }^{\circ} \mathrm{C}$ before further pretreatment in a wing mill refiner.

\section{Wing mill refiner (mixer)}

This equipment allows certain process parameters, such as temperature, residence time, and rotor mixing speed (rpm), to be controlled. Although the main purpose of the equipment is to mimic refining conditions, in this work, the wing mill refiner was used solely as a mixer (Fig. 1). Before sodium hydroxide $(\mathrm{NaOH})$ and hydrogen peroxide $\left(\mathrm{H}_{2} \mathrm{O}_{2}\right)$ pretreatment of the pulp fibres, the temperature of the wing mill refiner was set to $90{ }^{\circ} \mathrm{C} ; 150 \mathrm{~g}$ of o.d. pulp was placed in the vessel and preheated for $10 \mathrm{~min}$ at a rotor speed of $60 \mathrm{rpm}$. After this, the two chemicals were mixed together and charged via the nozzle at a pressure of 3 bars; immediately after the chemical dosage, the rotor speed was increased to $750 \mathrm{rpm}$ for $1 \mathrm{~min}$ to achieve effective mixing. The rotor speed was later reduced to the usual $60 \mathrm{rpm}$ for the rest of the 15 min reaction time. The samples were collected and stored in the refrigerator before further treatment. The reaction of the chemicals was stopped by diluting the mixture with distilled water and then subjecting it to a double fractionation process using a Britt Dynamic 

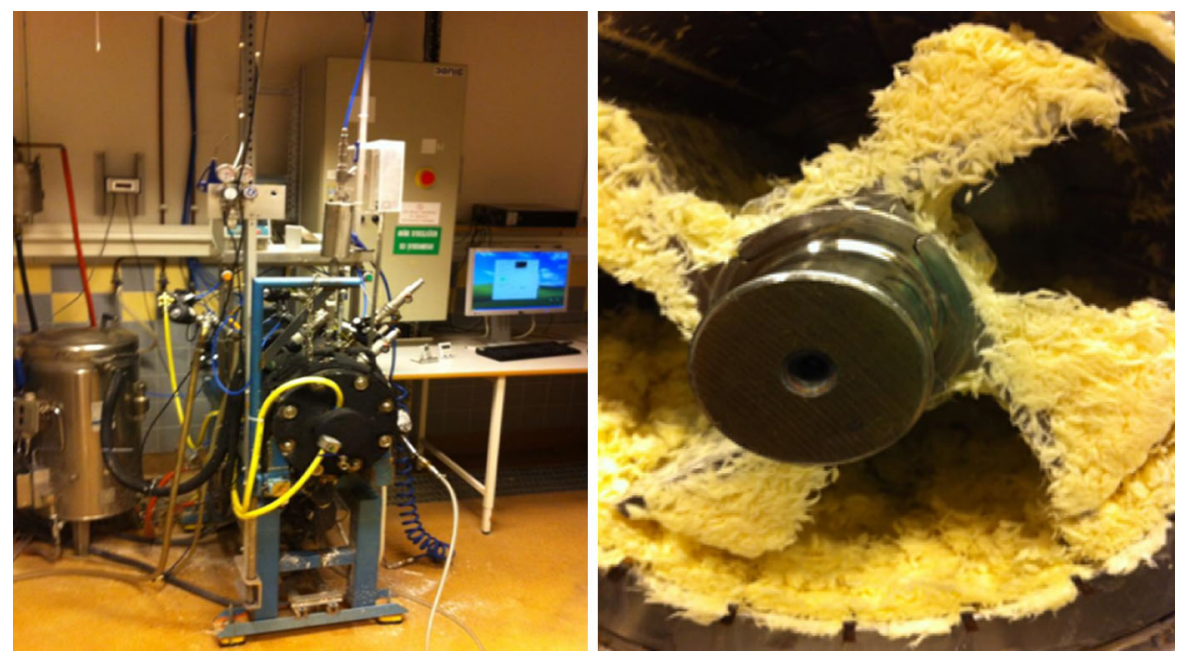

Fig. 1 Wing mill refiner, used as mixer in this work

Drainage Jar (BDDJ or BJ) using both the 30- and 100-mesh wire screens.

\section{Britt Dynamic Drainage Jar (BDDJ) fractionation}

In this paper, the pulps were fractionated using a specially designed 8-L BDDJ at the SCA Research Centre in Sundsvall. Pulps were disintegrated for 30,000 revolutions and diluted with $8 \mathrm{~L}$ of tap water. Thirty grams of o.d. pulp was used for each fractionation. The fine fractions were obtained from the pulp samples using the BDDJ fractionation technique in which fractions passing through the 30-mesh wire screen were regarded as "fines" while the fractions retained on the 30-mesh wire screen were discarded; a 100-mesh wire screen was also used for the fractionation process. The cut-off or pore size of the BDDJ 30 -mesh screen was approximately $600 \mu \mathrm{m}$. Fibre fractionation was conducted to obtain small, short fibres that could be easily homogenised.

\section{Homogenisation}

A Niro Soavi homogeniser (ARIETE, model NS2006H; GEA Group, Parma, Italy) was used to produce nano-ligno-cellulose. The high-pressure homogeniser subjects the pulp slurries to high impact forces and high shear rates due to the reciprocating action within the valves. The pulp suspension undergoes high-pressure micronisation, which reduces the fibre size to obtain a stable suspension. The homogenisation experiments in this study were performed using thermomechanical pulp and chemi-thermomechanical pulp fines. The pulp slurries were treated in the homogenising equipment at approximately $1 \%$ consistency for $120 \mathrm{~min}$ at a homogenisation pressure in the range of 200-300 bars for approximately 9 and 18 passes (homogenisation cycles). Before homogenisation, the pulp fibres were diluted with water to a solids content of approximately $1 \%$ Table 1 shows the process variables, Table 2 represents the chemical dosages used, Table 3 shows the codes names of various pulp samples and lastly Table 4 shows the code names of MFC samples.

\section{Scanning electron microscopy (SEM)}

To freeze-dry the MFC, pulp suspensions were first placed in moulds and then plunged into liquid propane for rapid freezing. Moulds containing frozen pulp specimens were transferred to a freeze dryer and allowed to dry for $24 \mathrm{~h}$. Freeze-dried pulp fibres and MFC were mounted on aluminium studs using doublesided carbon tape. Fibre specimens were sputtered with $\mathrm{Au} / \mathrm{Pd}$ particles in an Emitech K100X sputterer (Emitech, Fall River, MA, USA) for $1.5 \mathrm{~min}$ and then examined using a Zeiss Sigma VP scanning electron microscope (Zeiss, Oberkocken, Germany).

\section{Transmission electron microscopy (TEM)}

For transmission electron microscopy, a $20-\mu \mathrm{L}$ drop of pulp and MFC dispersion was placed on a QUANTIFOIL 400-mesh copper grid with holey carbon film 
Table 1 Conditions used in the hydrogen peroxide $\left(\mathrm{H}_{2} \mathrm{O}_{2}\right)$ and sodium hydroxide $(\mathrm{NaOH})$ pretreatment of CTMP and TMP the wing mill refiner (mixer)

\begin{tabular}{ll}
\hline Process variables & \\
Pulp consistency $(\%)$ & Approx. $18 \%$ \\
Total time $(\mathrm{min})$ & 25 \\
Temperature $\left({ }^{\circ} \mathrm{C}\right)$ & 90 \\
High chemical dosage $(\%)$ & 4 \\
Low chemical dosage $(\%)$ & 1 \\
Wing mill refiner mixing speed $(\mathrm{rpm})$ & \\
High mixing speed $(\mathrm{rpm})$ & 750 for 1 min \\
Low mixing speed $(\mathrm{rpm})$ & 60 for 10 min and later 60 for 15 min
\end{tabular}

Table 2 Chemical pretreatment: chemical type and dosage

\begin{tabular}{lc}
\hline Chemical pre-treatment: chemical type and dosage \\
\hline Sodium hydroxide $(\mathrm{NaOH})$ & $6 \mathrm{~kg} / \mathrm{t}$ \\
Low dosage & $24 \mathrm{~kg} / \mathrm{t}$ \\
High dosage & \\
Hydrogen peroxide $\left(\mathrm{H}_{2} \mathrm{O}_{2}\right)$ & $10 \mathrm{~kg} / \mathrm{t}$ \\
Low dosage & $40 \mathrm{~kg} / \mathrm{t}$ \\
High dosage & $10 \mathrm{~kg} / \mathrm{t}$ \\
Diethylenetriamine penta-acetic acid (DTPA) \\
Dosage
\end{tabular}

(EMS, Hatfield, PA, USA). The excess solution was blotted with a filter paper and the dispersion was allowed to dry. Grids with pulp specimens were examined using an FEI Tecnai 12 transmission electron microscope (FEI, Hillsboro, OR, USA) at an accelerating voltage of $120 \mathrm{kV}$.

\section{Pulps for section 2}

The NFC was produced from a chemi-thermomechanical pulp (CTMP) (SCA Östrand Pulp Mill, Sundsvall, Sweden) and from a commercial sulphite softwood dissolving pulp (SP) (Domsjö Fabriker AB, Örnsköldsvik, Sweden) with very low contents of hemicellulose $(<5 \%)$ and lignin $(<1 \%)$.

\section{MFC processing for section 2}

TEMPO-mediated oxidation was conducted using never-dried CTMP and SP according to the method described by Saito et al. (2006). The chemical oxidations were conducted using $\mathrm{NaClO}, \mathrm{NaBr}$, and TEMPO catalyst. The dosages of $\mathrm{NaClO}$ used in these trials were as follows: $0,3,5,7$, and $10 \mathrm{mmol}$ $\mathrm{NaClO} \mathrm{g}^{-1}$ of cellulose. The $\mathrm{pH}$ was kept at $9-10$ by adjustment with $\mathrm{NaOH}$ or $\mathrm{HCl}$ and the reaction time for the chemical oxidation was approximately $2 \mathrm{~h}$. After the TEMPO-mediated oxidation, the pulp suspensions were thoroughly washed with distilled water and mechanically treated using the T-25 ULTRATURRAX high-speed homogeniser (IKA, Wilmington, NC, USA) to produce NFC. The homogenising equipment was set at 20,000 rpm for 30,60 , and $90 \mathrm{~min}$.

\section{Crill measurement}

It is worth noting that the ability of the crill analyser to measure nano-size particle is limited. However, main objective of the crill qualitative study was to lay a foundation for developing a rapid and robust method for a continuous online and/or offline monitoring system during the processing of nanocellulose. The method analyses the interaction between fibres and microfibrils (crill) and is based on the optical response of a suspension at two wavelengths of light, UV (this is capable of detecting tiny particles in range of approximately $100-250 \mathrm{~nm}$ and IR (this is capable of detecting coarse particles above $900 \mathrm{~nm}$ ). In this work a PulpEye Analyser (PulpEye, Örnsköldsvik, Sweden) was used in evaluating the degree of fibrillation of the cellulosic nanoparticles. For all crill value measurements, we used $1 \mathrm{~g}$ (dry solid content) of the NFC suspension. The PulpEye analyser gives a qualitative idea of the fibrillation efficiency of an NFC suspension. More on crill methodology can be read in Osong et al. (2014), Pettersson (2010), and Steenberg et al. (1960). The crill method possesses the inherent ability to characterise particle size of a microfibril/nanofibril within a very short time frame (i.e., a few seconds) and 
Table 3 Code names of hydrogen peroxide-pretreated pulp samples and their fractionation stages

\begin{tabular}{llll}
\hline Code & Fractionated samples (BJ 30 and BJ 100) & Hydrogen peroxide dosage (\%) & Rejected or accepted fraction \\
\hline AA1 & TMP whole pulp (non-fractionated) & 0 & Rejected \\
AA2 & TMP BJ30 & 0 & Rejected \\
AA3 & TMP BJ100 & 0 & Rejected \\
AA4 & TMP BJ30 & 4 & Rejected \\
AA5 & TMP BJ30 & 1 & Rejected \\
AA6 & TMP BJ100 & 4 & Rejected \\
AA7 & TMP BJ100 & 1 & Accepted \\
AA8 & TMP BJ100 & 4 & Accepted \\
AA9 & TMP BJ100 & 1 & Accepted \\
AA10 & TMP BJ100 & 0 & \\
BB20 & CTMP whole pulp (non-fractionated) & & Rejected \\
BB21 & CTMP BJ30 & 0 & Rejected \\
BB22 & CTMP BJ100 & 0 & Rejected \\
BB23 & CTMP BJ30 & 4 & Rejected \\
BB24 & CTMP BJ30 & 1 & Rejected \\
BB25 & CTMP BJ100 & 4 & Rejected \\
BB26 & CTMP BJ100 & 1 & Accepted \\
BB27 & CTMP BJ100 & & Accepted \\
BB28 & CTMP BJ100 & 4 & Accepted \\
BB29 & CTMP BJ100 & 1 &
\end{tabular}

Table 4 Code names of hydrogen peroxide-pretreated MFC samples

\begin{tabular}{ll}
\hline Pulp type & Code \\
\hline $4 \%$ peroxide bleached TMP & C18 \\
$1 \%$ peroxide bleached TMP & D18 \\
Non-treated bleached TMP & E18 \\
Non-treated bleached CTMP & F18 \\
$4 \%$ peroxide bleached CTMP & G18 \\
$1 \%$ peroxide bleached CTMP & H18 \\
\hline
\end{tabular}

Here "18" refers to the number of homogenisation passes

without any damage to the nanocellulose suspension under investigation, making it a non-destructive method. It should be noted that using this method to evaluate nanocellulose makes it possible to reduce the use of time-consuming microscopy techniques used in evaluating different nanocellulose qualities. Figure $2 \mathrm{a}, \mathrm{b}$ shows schematics of the crill measurement principle. The crill value is dependent on the transmittance of light, and the transmittance is a function of absorption, light scattering and concentration of the particles in the suspension. Higher crill value would means more particles per volume, thereby increasing the signal in the UV wavelength of light.

\section{Results and discussion}

\section{Section 1}

This article is divided into two sections: the first deals with the hydrogen peroxide pretreatment strategy combined with high-pressure homogenisation to produce TMP- and CTMP-based MFC; the second deals with the use of the TEMPO-mediated oxidation method to produce well fibrillated and individualised MFC. Crill refer to hairy fibrils on pulp fibre surfaces or to loose slender and fibrillar micro-particles (Steenberg et al. 1960). The crill methodology is based on the optical response of a suspension to two different wavelengths of light, UV and IR. The UV 
Fig. 2 a Theory and background of the crill measurement method. b Schematic of the crill measurement principle, where UV/IR = crill value (Hansen and Sundvall 2012)

(a)

Measurement cell

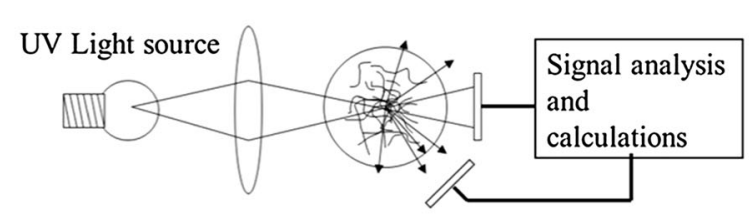

Detection of transmitted and scattered light

Measurement cell

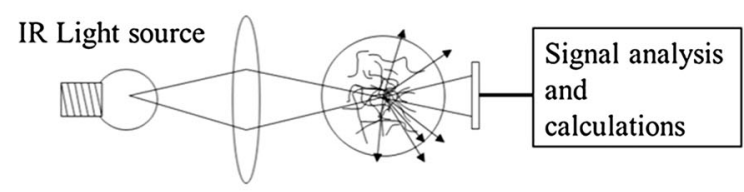

Detection of transmitted and scattered light

(b)
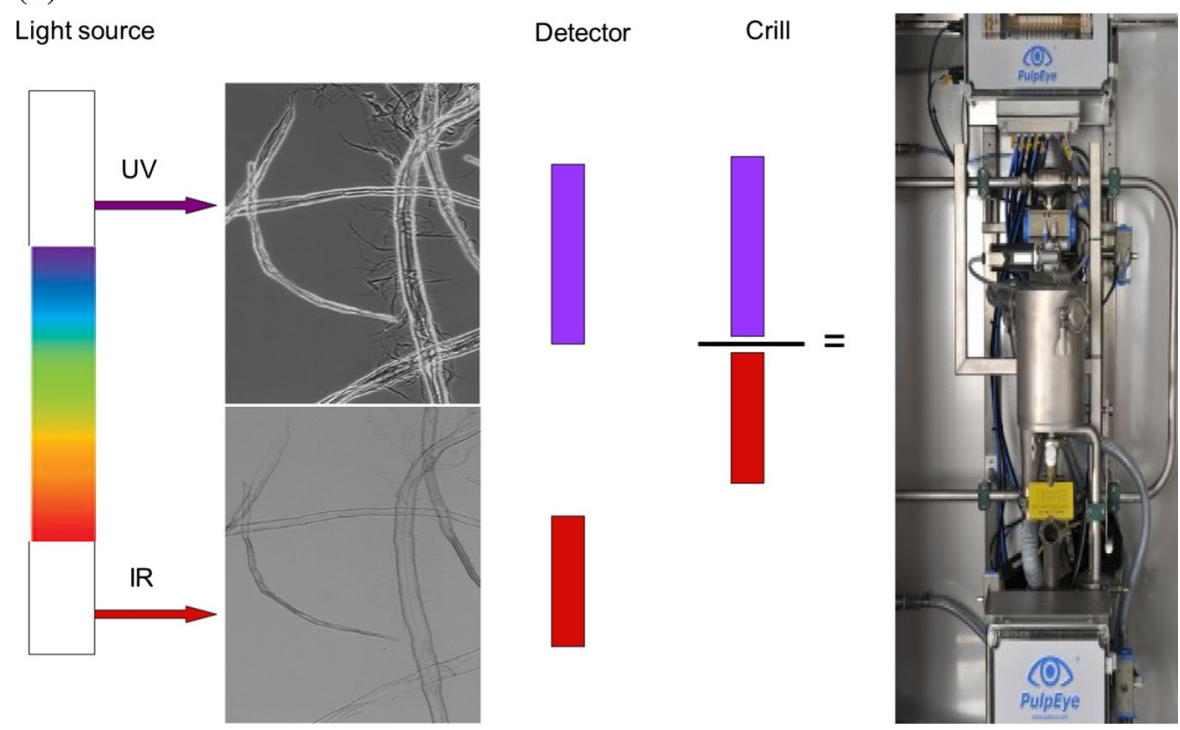

striking the crill provides information about both the fibres and nanofibrils (crill), while the IR provides information about only the fibres. The crill value is therefore a concentration-independent ratio of UV and IR measurements. Some aspects of the fibre pretreatment strategy improve fibrillation performance during microfibrillated cellulose production, including interactions among the chemical components (i.e., lignin, cellulose, and hemicellulose) of wood pulp fibres of TMP and CTMP and the effects of the sodium hydroxide and hydrogen peroxide pretreatment. To improve the fibrillation efficiency and prevent fibre clogging in the homogenisation equipment, it is necessary to pretreat these lignin-rich fibres to improve their swellability and weaken the cohesive forces between them. There is a need to work on such a pretreatment method to attain more efficient fibrillation in the homogeniser.

Our results indicate that it is possible to use hydrogen peroxide acid pretreatment combined with high-shear homogenisation to strategically produce nanocellulosic structures, and that the method can 
easily be upscaled. The results obtained so far indicate that we can successfully process nanocellulose. It was simple and clear to see from the SEM images that we had reduced the particle size of the fibres after mechanical treatment. We have previously reported that TMP can easily be softened at elevated temperatures due to the presence of lignin in the fibres. The softening of the lignin, however, does not seem to improve the fibrillation efficiency; it could be that the lignin serves to "glue" together the cellulose and hemicellulose, hindering proper fibrillation (Osong et al. 2013).

For the non-homogenised TMP samples, we noticed that the crill value was 210 units with $1 \%$ hydrogen peroxide pretreatment, increasing to 218 units with $4 \%$ hydrogen peroxide pretreatment, for an improvement of 8 units (Fig. 3). For the ninehomogenisation-cycle TMP-MFC samples, the crill value was 225 units with $1 \%$ hydrogen peroxide pretreatment, increasing to 228 units with $4 \%$ hydrogen peroxide pretreatment, for an improvement of three units. The 18-homogenisation-cycle TMP-MFC sample displayed an improvement of 2 crill units relative to the 1 and $4 \%$ hydrogen peroxide pretreatments (Fig. 3).

For the non-homogenised CTMP samples, we noticed that the crill value was 205 units with $1 \%$ hydrogen peroxide pretreatment, increasing to 214 units with $4 \%$ hydrogen peroxide pretreatment, for an

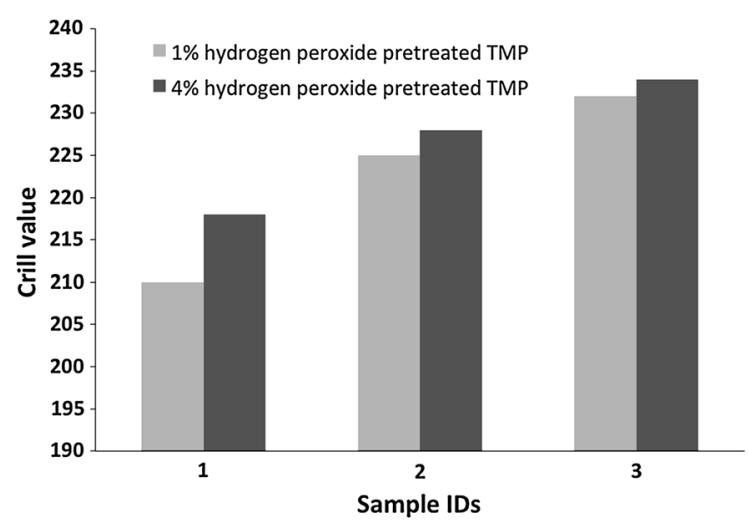

Fig. 3 Crill values of TMP-based MFC relative to chemical (i.e., hydrogen peroxide) treatment and homogenisation cycles. Note: Here "sample 1" is non-homogenised, "sample 2" is homogenised at 9-cycles and "sample 3" at 18-cycles

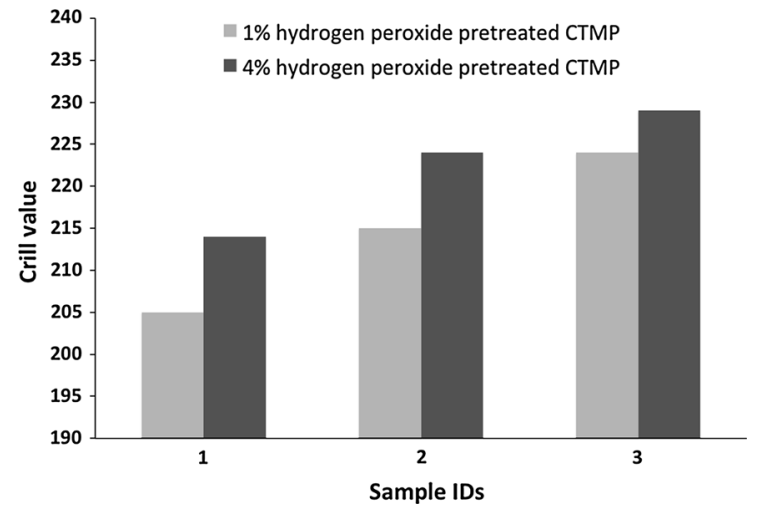

Fig. 4 Crill values of CTMP-based MFC relative to chemical (i.e., hydrogen peroxide) pretreatment and homogenisation cycles. Note: Here "sample 1" is non-homogenised, "sample 2" is homogenised at 9-cycles and "sample 3" at 18-cycles

improvement of nine units (Fig. 4). For the ninehomogenisation-cycle CTMP-MFC samples, the crill value was 215 units with $1 \%$ hydrogen peroxide pretreatment, increasing to 224 units that with $4 \%$ hydrogen peroxide pretreatment, for an improvement of nine units. The 18 homogenisation cycles of CTMPMFC displayed an improvement of 5 crill units relative to the 1 and $4 \%$ hydrogen peroxide pretreatments.

When considering the number of homogenisation passes versus the non-homogenised reference samples, we noticed that with $1 \%$ hydrogen peroxide pretreatment, the crill values for the untreated samples were 210 and 205 units for the TMP and CTMP samples, respectively, and that after 18 homogenisation passes, the crill values increased to 232 and 224 units for the TMP and CTMP samples, respectively, for a 22-unit improvement for the TMP and a 19-unit improvement for the CTMP samples. With $4 \%$ hydrogen peroxide pretreatment, the crill values for the untreated samples were 218 and 214 units for the TMP and CTMP samples, respectively, increasing to 234 and 229 units after 18 homogenisation passes for the TMP and CTMP samples, respectively, for a 16-unit improvement for the TMP and a 15-unit improvement for the CTMP samples. The SEM and TEM images (Figs. 5, 6, 7) show the improved fibrillation of the fibres after fractionation using the BDDJ and homogenisation process. Figure 7 shows 
(a)

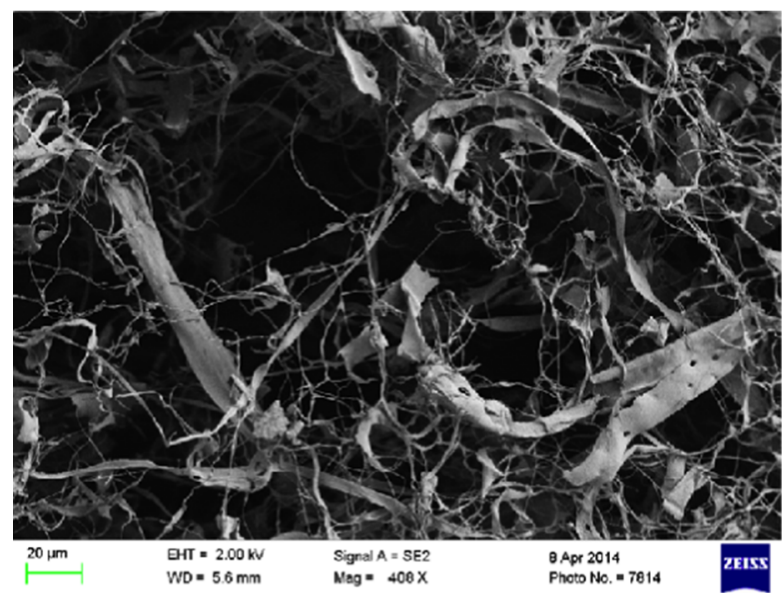

(b)

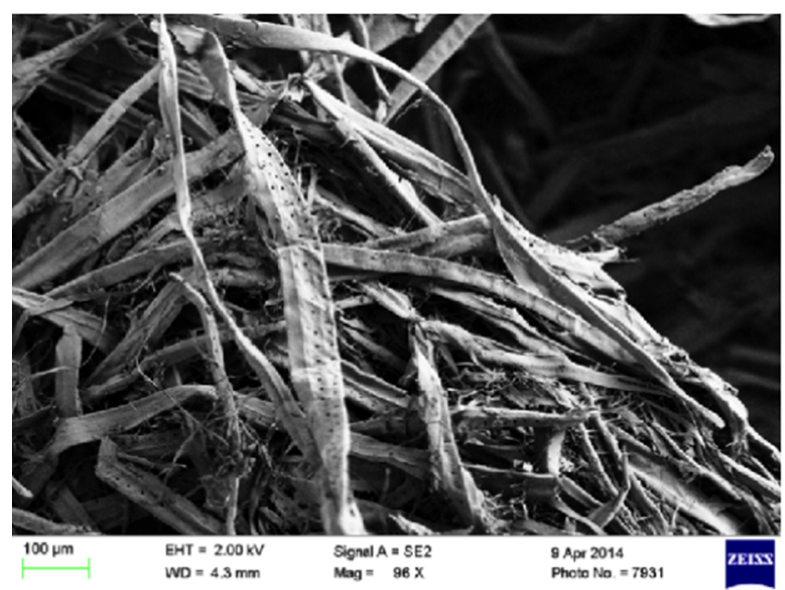

(c)

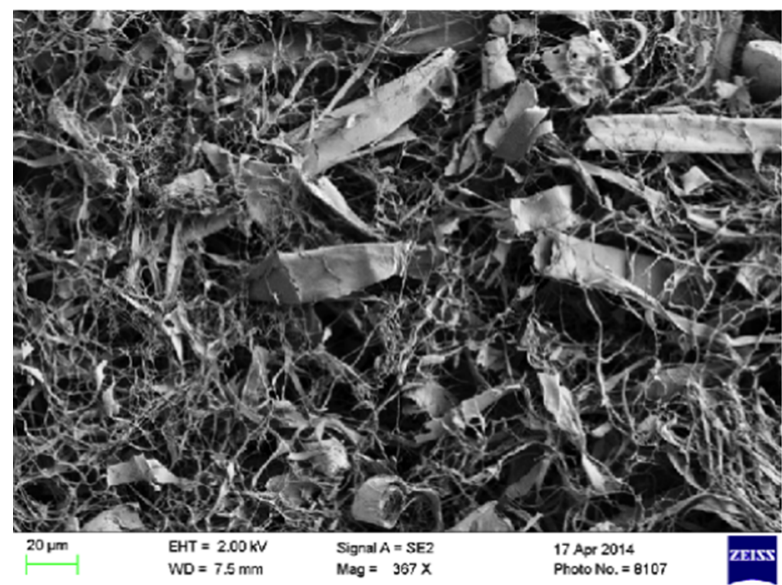

Fig. 5 a SEM images of TMP-BJ100, accepted, samples: first image is of sample AA8 (4\% peroxide treated) and the second is of sample AA9 (1\% peroxide treated). b SEM images of CTMP-BJ30, rejected, samples: first image is of sample BB21 (untreated coarse, longer fibres) and the second is of sample
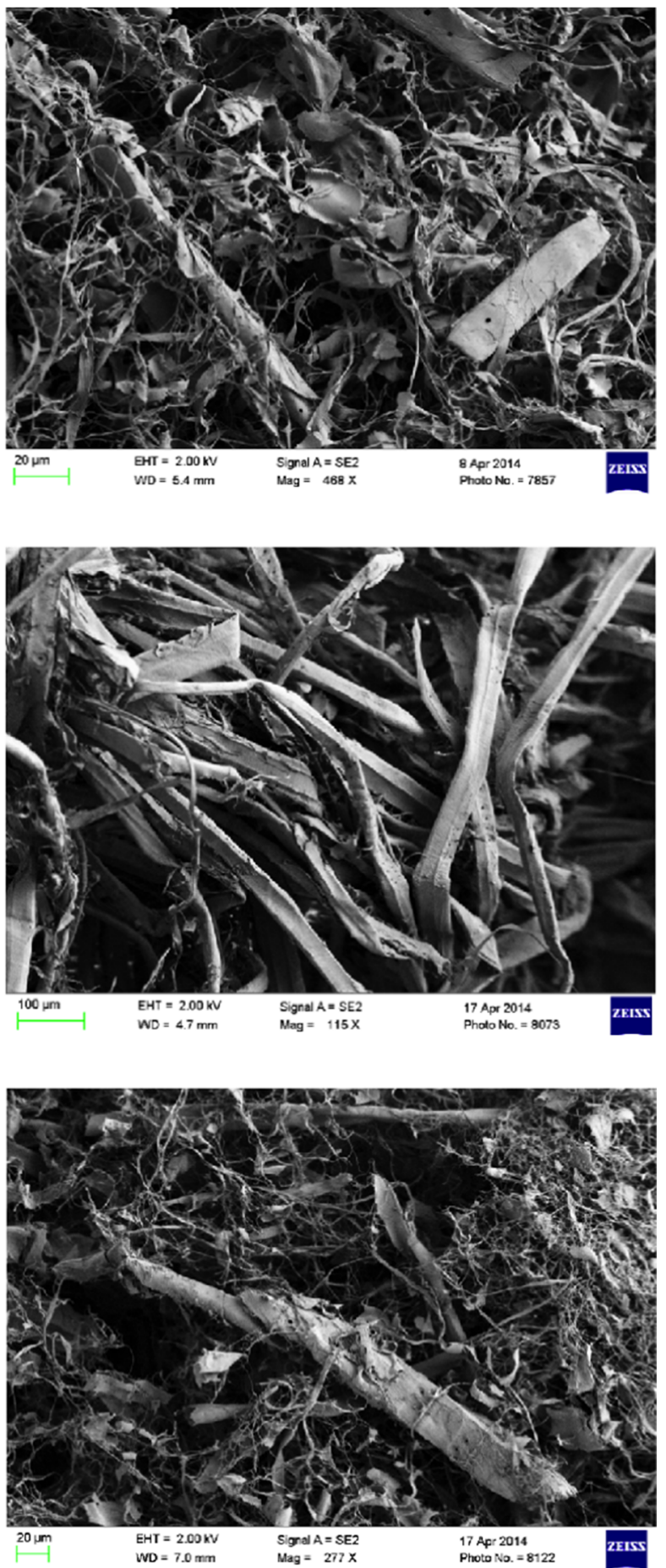

BB24 (1\% peroxide treated). c SEM images of CTMP-BJ100, accepted, samples: first image is of sample BB27 (4\% peroxide treated) and the second is of sample BB28 (1\% peroxide treated) 
(a)
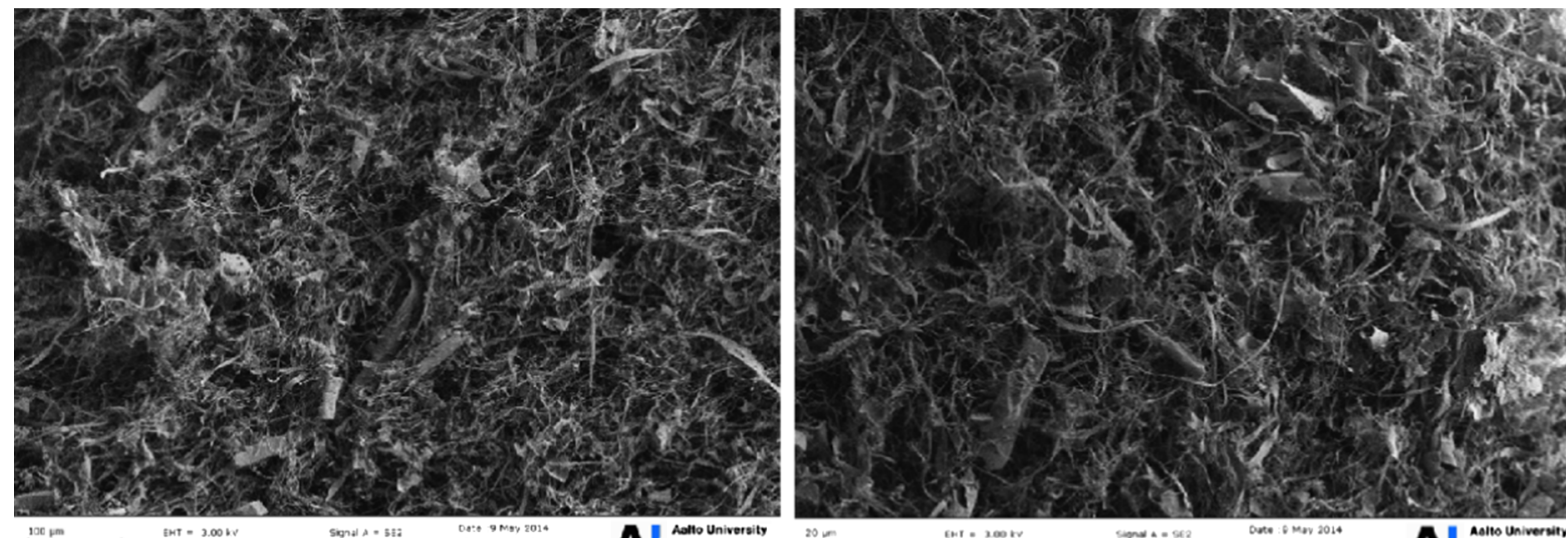

$\longmapsto$

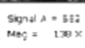

Ims : : 2 2:00s

A. Aollo Univeraity

2004

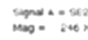

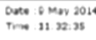

A. Aollo universily

(b)
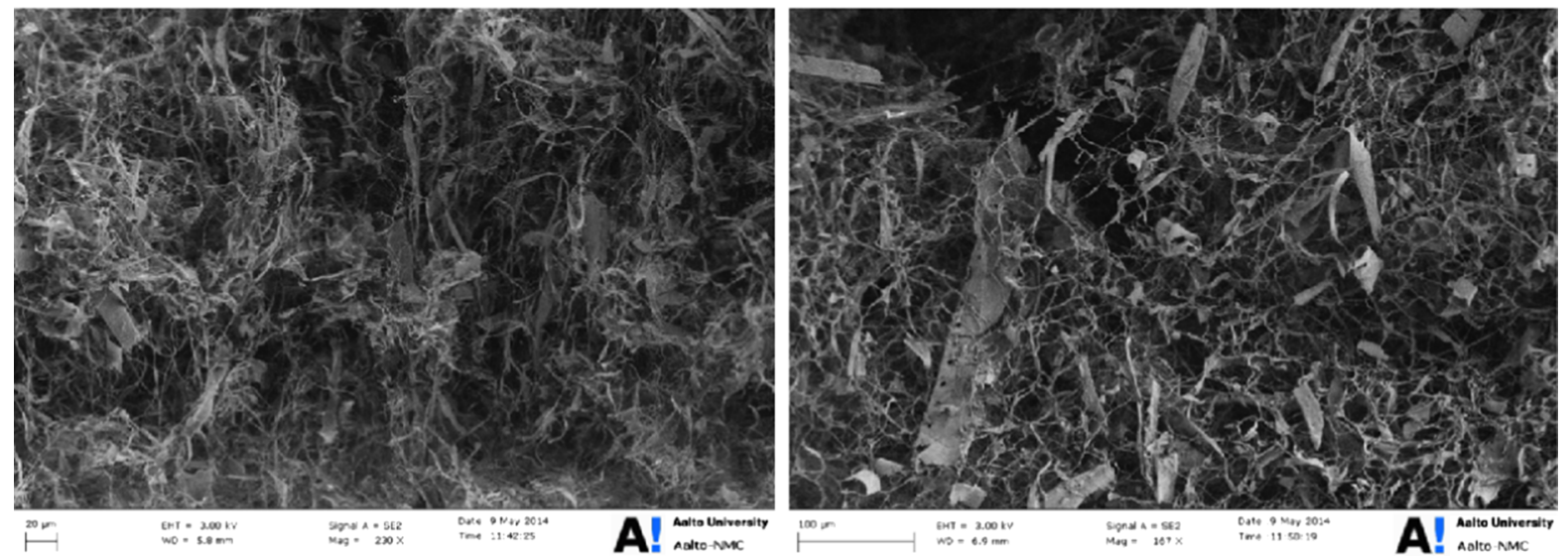

1000

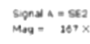

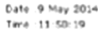

A! Aolto University

(c)
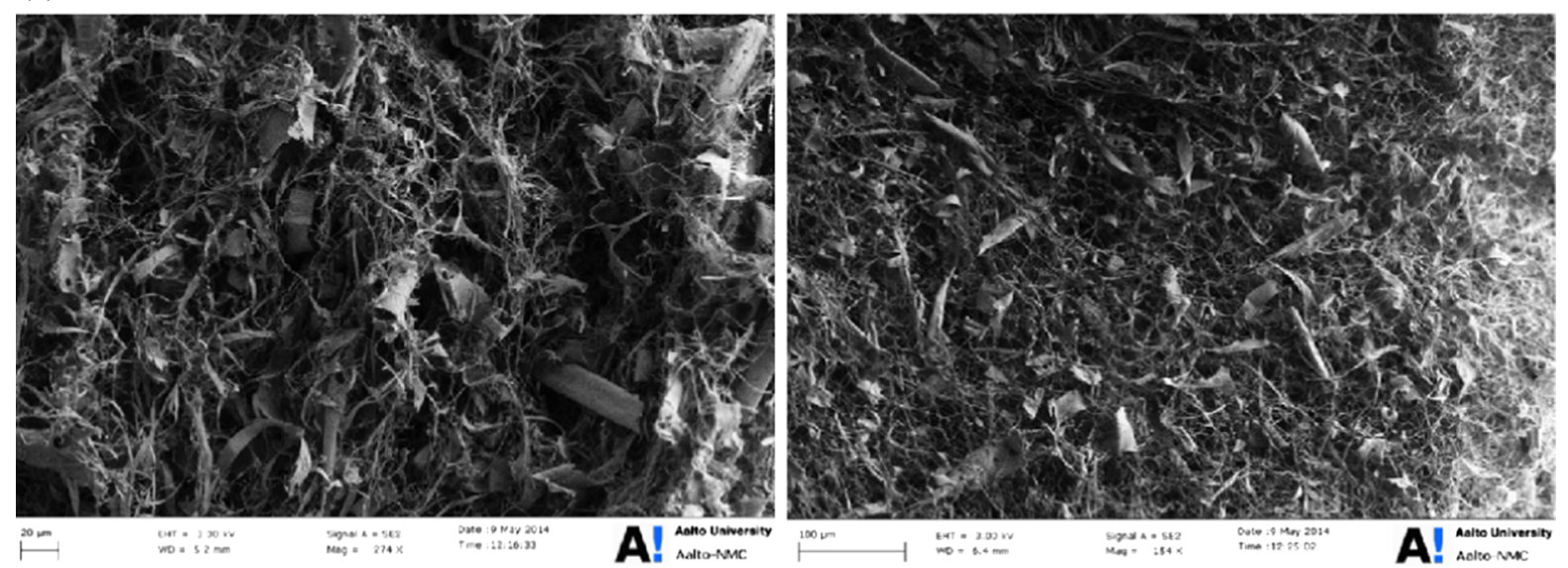

Fig. 6 a SEM images of TMP-based MFC samples: first image is of sample $\mathrm{C} 18$ (4\% peroxide treated) and the second is of sample D18 (1\% peroxide treated). b SEM images of TMPbased MFC samples: first image is of sample E18 (untreated)

and the second is of sample F18 (untreated). c SEM images of CTMP-based MFC samples: first image is of sample G18 (4\% peroxide treated) and the second is of sample H18 (1\% peroxide treated) 

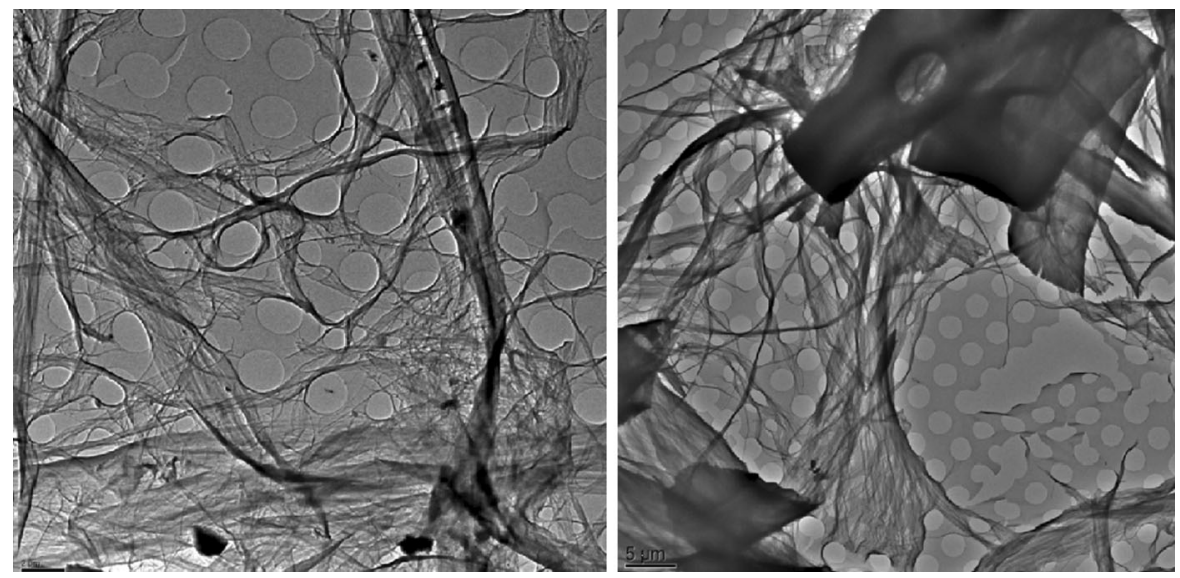

Fig. 7 TEM images of TMP-based MFC and CTMP-based MFC samples, respectively: the first image is of sample D18 (1 \% peroxide treated TMP-MFC) and the second is of sample F18 (untreated CTMP-MFC)

how the fibrils have become "glued" into fibrillar bundles due to the presence of lignin.

\section{Section 2}

The high fibrillation efficiency is a well-known advantage of the TEMPO-based nanocellulose process; accordingly, in this work we compare the crill values with the homogenisation times and chemical treatment dosages. In making such comparisons, one can clearly see that the crill values improve with higher $\mathrm{NaClO}$ dosages and longer mechanical treatment times. It is well known that the TEMPO method converts the hydroxyl group of cellulose into corresponding carboxylate groups and some aldehyde groups, thereby introducing negatively charged groups on the surface of the cellulose chain. The TEMPO oxidation of lignin-rich pulps (e.g., TMP) requires the addition of more $\mathrm{NaClO}$ to obtain the same level of oxidation for fibres with high cellulose contents above $90 \%$ (Okita et al. 2009). TEMPO oxidation is selective for primary alcohols (De Nooy et al. 1995) and the isolation of individual MFCs is enabled by the electrostatic repulsion between fibrils. Lignin is dissolved during TEMPO-mediated oxidation (Ma and Zhai 2013), affecting the consumption of $\mathrm{NaClO}$ and thereby the degree of fibrillation. The dosage of $\mathrm{NaClO}$ and the duration of mechanical homogenisation might therefore need to be adjusted to obtain complete fibrillation of CTMP.

That it is relatively easy to produce well-fibrillated nanofibrils from chemical pulps (e.g., sulphite pulp) is obvious in light of current knowledge. However, enormous challenges are still encountered when using mechanical pulps (i.e., CTMP and TMP) because the lignin serves to "glue" together cellulose and hemicellulose, hindering effective fibrillation during mechanical shearing. To widen the applications of CTMP and TMP, it is crucial to use these materials in the production of microfibrillated cellulose. In addition, the TEMPO reaction is usually conducted at high $\mathrm{pH}$ (9-10); during the reaction, we noticed a reduction in brightness (i.e., a pulp-yellowing effect) in the lignin-rich CTMP fibres. It is possible that the $\mathrm{NaClO}$ added to the pulp as a bleaching agent also generates chromophore groups on the lignin in alkaline media, leading to a change in colour.

For the non-pretreated SP-MFC samples, we noticed that at $0 \mathrm{~min}$ of homogenisation, the crill value was 130 units, and that after 90 min of treatment in the high-shear homogeniser, the crill value increased to 207 units for a $37 \%$ improvement of 77 crill units, as shown in Fig. 8. For the $3 \mathrm{mmol} \mathrm{NaClO}$ SP-MFC samples, the crill value at 0 min was 103 units, which increased to 320 units after 90 min of treatment for a $210 \%$ improvement of 217 crill units. For the $5 \mathrm{mmol} \mathrm{NaClO} \mathrm{SP-MFC} \mathrm{samples,} \mathrm{the} \mathrm{crill}$ value at $0 \mathrm{~min}$ of homogenisation was 108 units, which increased to 355 units after 90 min of treatment for a $228 \%$ improvement of 247 crill units. For the $7 \mathrm{mmol} \mathrm{NaClO}$ SP-MFC samples, the crill value at $0 \mathrm{~min}$ of homogenisation was 105 units, which increased to 294 units after 90 min of treatment for a $180 \%$ improvement of 189 crill units. Finally, for the 


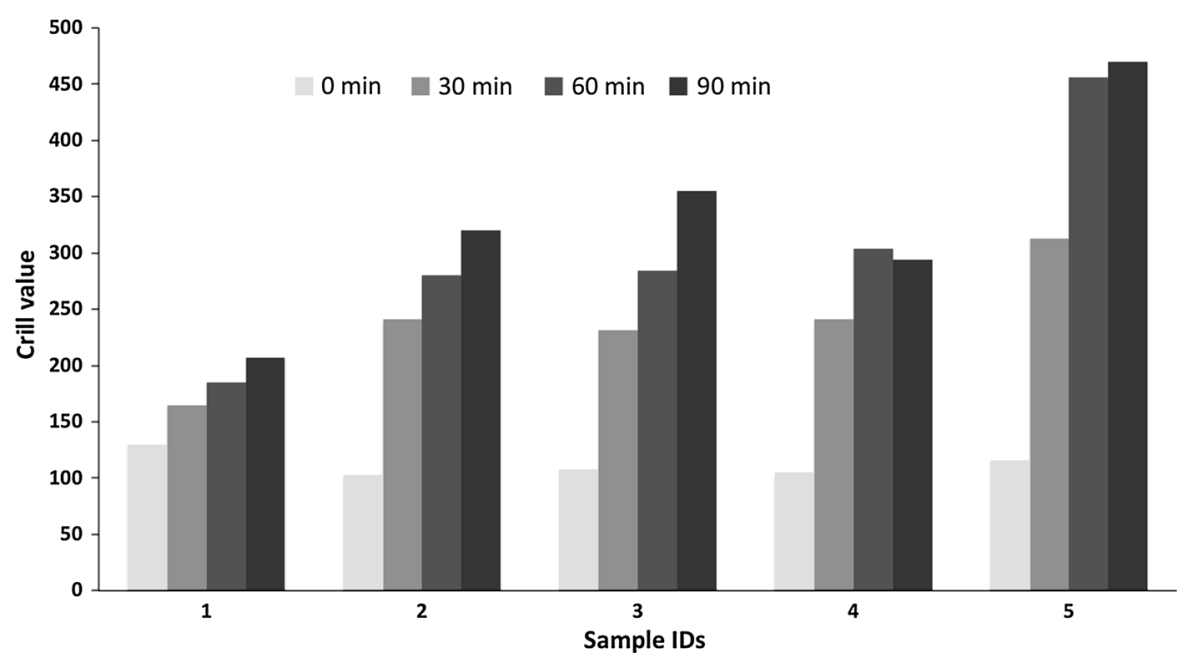

Fig. 8 Crill values of SP-based MFC relative to chemical (i.e., TEMPO) treatment and high-shear homogenisation time rill values of SP-based MFC in relation to chemical (TEMPO) and high-shear homogenisation time. Here "sample 1" is non-

$10 \mathrm{mmol} \mathrm{NaClO}$ SP-MFC samples, the crill value at 0 min was 116 units, which increased to 470 units after $90 \mathrm{~min}$ of treatment, for a $305 \%$ improvement of 354 crill units.

Almost the same improvement trend was noticed for the CTMP-based MFC samples, as shown in Fig. 9, after 30 and 90 min of high-shear homogenisation. The CTMP non-pretreated samples had a crill chemical pretreated, "sample 2 " is $3 \mathrm{mmol} \mathrm{NaClO}$ TEMPO pretreated, "sample 3" is $5 \mathrm{mmol} \mathrm{NaClO}$ TEMPO pretreated, "sample 4" is $7 \mathrm{mmol} \mathrm{NaClO}$ TEMPO pretreated, "sample 5" is $10 \mathrm{mmol} \mathrm{NaClO}$ TEMPO pretreated

value of 259 units after $30 \mathrm{~min}$ of treatment and of 333 units after $90 \mathrm{~min}$, for an improvement of 74 crill units. The $3 \mathrm{mmol} \mathrm{NaClO}$ CTMP-NFC samples had a crill value of 266 units after $30 \mathrm{~min}$ of treatment and of 322 units after $90 \mathrm{~min}$, for an improvement of 56 crill units. The $5 \mathrm{mmol} \mathrm{NaClO}$ CTMP-MFC samples had a crill value of 261 units after $30 \mathrm{~min}$ of treatment and of 317 units after at $90 \mathrm{~min}$, for an improvement of 56

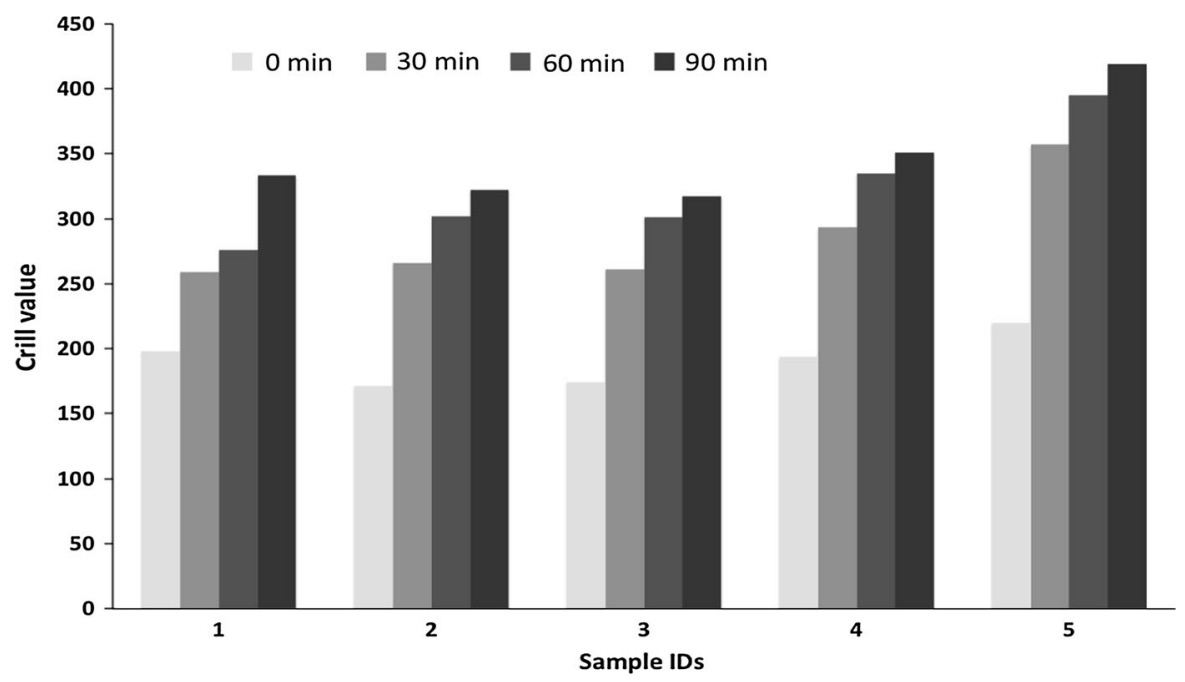

Fig. 9 Crill values of CTMP-based MFC relative to chemical (i.e., TEMPO) treatment and high-shear homogenisation time. Here "sample 1" is non-chemical pretreated, "sample 2" is $3 \mathrm{mmol} \mathrm{NaClO}$ TEMPO pretreated, "sample 3 " is $5 \mathrm{mmol}$
$\mathrm{NaClO}$ TEMPO pretreated, "sample 4 " is $7 \mathrm{mmol} \mathrm{NaClO}$ TEMPO pretreated, "sample 5" is $10 \mathrm{mmol} \mathrm{NaClO}$ TEMPO pretreated 
crill units. The $7 \mathrm{mmol} \mathrm{NaClO}$ CTMP-MFC samples had a crill value of 293 units after 30 min of treatment and of 351 units after $90 \mathrm{~min}$, for an improvement of 58 crill units. Finally, the $10 \mathrm{mmol} \mathrm{NaClO} \mathrm{CTMP-}$ MFC samples had a crill value of 357 units after $30 \mathrm{~min}$ of treatment and of 419 units after $90 \mathrm{~min}$, for an improvement of 62 crill units.

\section{Conclusion}

We successfully produced MFC through two different processing routes, i.e., hydrogen peroxide pretreatment and TEMPO-mediated oxidation. We conclude from the improvement in crill values that there is better potential to produce MFC using the TEMPO method than using hydrogen peroxide pretreatment, as the process yields a uniform size distribution of nanocellulose microfibrils under $100 \mathrm{~nm}$ in size. Using this method, it is possible to process highconsistency pulp fibres via what can be seen as a lowenergy fibrillation process. We conclude that the TEMPO-mediated oxidation method enables the fibres to swell, resulting in a high proportion of wellindividualised nanofibrils with a very high aspect ratio. The crill values of the TMP and CTMP samples prepared using the hydrogen peroxide strategy indicate very small improvements in samples of both pulp types, and changing the treatment time and hydrogen peroxide dosage did not result in any significant improvement. When using the TEMPO-assisted method, however, both increased treatment times and higher $\mathrm{NaClO}$ dosages in the TEMPO system significantly improved the crill values and fibrillation efficiency. The SEM and TEM images clearly showed that the fibrillar state of both the TMP- and CTMPbased MFC improved with Britt jar fractionation and homogenisation.

Acknowledgments This work was financially supported by the KK-Foundation in collaboration with MoRe Research and Mid Sweden University as part of the programme Forest as a Resource Industrial Research College (FORIC) at Mid Sweden University.

Open Access This article is distributed under the terms of the Creative Commons Attribution 4.0 International License (http:// creativecommons.org/licenses/by/4.0/), which permits unrestricted use, distribution, and reproduction in any medium, provided you give appropriate credit to the original author(s) and the source, provide a link to the Creative Commons license, and indicate if changes were made.

\section{References}

Brodin FW, Eriksen $\varnothing$ (2014) Preparation of individualised lignocellulose microfibrils based on thermomechanical pulp and their effect on paper properties. Nord Pulp Pap Res J 30(3):443-451

Charreau H, Foresti ML, Vázquez A (2013) Nanocellulose patents trends: a comprehensive review on patents on cellulose nanocrystals, microfibrillated and bacterial cellulose. Recent Pat Nanotechnol 7(1):56-80

De Nooy AEJ, Besemer AC, Van Bekkum H (1995) Highly selective nitroxyl radical-mediated oxidation of primary alcohol groups in water-soluble glucans. Carbohydr Res 269(1):89-98

Eichhorn SJ, Dufresne A, Aranguren M, Marcovich NE, Capadona JR, Rowan SJ, Weder C, Thielemans W, Roman M, Renneckar S, Gindl W, Veigel S, Keckes J, Yano H, Abe K, Nogi M, Nakagaito AN, Mangalam A, Simonsen J, Benight AS, Bismarck A, Berglund LA, Peijs T (2010) Review: current international research into cellulose nanofibres and nanocomposites. J Mater Sci 45(1):1-33

Hansen P, Sundvall Ö (2012) On-line crill sensor commercially available 2012. In: International paper physics and 8th international paper and coating chemistry conference Stockholm Sweden, June 10-14 2012, poster

Herrick FW, Casebier RL, Hamilton JK, Sandberg KR (1983) Microfibrillated cellulose: morphology and accessibility. In: Journal of applied polymer science: applied polymer symposium, vol 37, Syracuse, NY, USA, pp 797-813

Hubbe MA, Rojas OJ, Lucia LA, Sain M (2008) Cellulosic nanocomposites: a review. BioResources 3(3):929-980

Hyll K (2015) Size and shape characterization of fines and fillers-a review. Nord Pulp Pap Res J 30(3):466-487

Isogai A (2013) Wood nanocelluloses: fundamentals and applications as new bio-based nanomaterials. J Wood Sci 59(6):449-459

Isogai A, Saito T, Fukuzumi H (2011a) TEMPO-oxidized cellulose nanofibers. Nanoscale 3(1):71-85

Isogai T, Saito T, Isogai A (2011b) Wood cellulose nanofibrils prepared by TEMPO electro-mediated oxidation. Cellulose 18(2):421-431

Khalil HPSA, Bhat AH, Yusra AFI (2012) Green composites from sustainable cellulose nanofibrils: a review. Carbohydr Polym 87(2):963-979

Klemm D, Kramer F, Moritz S, Lindström T, Ankerfors M, Gray D, Dorris A (2011) Nanocelluloses: a new family of naturebased materials. Angew Chem Int Ed 50(24):5438-5466

Lahtinen P, Liukkonen S, Pere J, Sneck A, Kangas H (2014) A comparative study of fibrillated fibers from different mechanical and chemical pulps. BioResources 9(2):2115-2127

Ma P, Zhai H (2013) Selective TEMPO-mediated oxidation of thermomechanical pulp. BioResources 8(3):4396-4405 
Moon RJ, Martin A, Nairn J, Simonsen J, Youngblood J (2011) Cellulose nanomaterials review: structure, properties and nanocomposites. Chem Soc Rev 40:3941-3994

Okita Y, Saito T, Isogai A (2009) TEMPO-mediated oxidation of softwood thermomechanical pulp. Holzforschung 63:529-535

Osong SH, Norgren S, Engstrand P (2013) An approach to produce nano-ligno-cellulose from mechanical pulp fine materials. Nord Pulp Pap Res J 28(4):472-479

Osong SH, Norgren S, Engstrand P, Lundberg M, Hansen P (2014) Crill: a novel technique to characterize nano-lignocellulose. Nord Pulp Pap Res J 29(2):190-194

Pääkkö M, Ankerfors M, Kosonen H, Nykänen A, Ahola S, Österberg M, Ruokolainen J, Laine J, Larsson PT, Ikkala O, Lindström T (2007) Enzymatic hydrolysis combined with mechanical shearing and high-pressure homogenization for nanoscale cellulose fibrils and strong gels. Biomacromolecules 8(6):1934-1941

Pettersson T (2010) On-line crill measurements for improved control of refining. In: Control systems 2010, SPCI, Stockholm

Saito T, Nishiyama Y, Putaux JL, Vignon M, Isogai A (2006) Homogeneous suspensions of individualized microfibrils from TEMPO-catalyzed oxidation of native cellulose. Biomacromolecules 7:1687-1691

Saito T, Kimura S, Nishiyama Y, Isogai A (2007) Cellulose nanofibers prepared by TEMPO-mediated oxidation of native cellulose. Biomacromolecules 8(8):2485-2491

Siró I, Plackett D (2010) Microfibrillated cellulose and new nanocomposite materials: a review. Cellulose 17(3):459-494

Spence KL, Venditti RA, Habibi Y, Rojas OJ, Pawlak JJ (2010) The effect of chemical composition on microfibrillar cellulose films from wood pulps: mechanical processing and physical properties. Bioresour Technol 101(15):5961-5968

Steenberg B, Sandgren B, Wahren D (1960) Studies on pulp crill, part 1. Suspended fibrils in paper pulp fines. Svensk Papperstidning Nr 12:395-397

Turbak AF, Snyder FW, Sandberg KR (1983) Microfibrillated cellulose, a new cellulose product: properties, uses, and commercial potential. In: Journal of applied polymer science: applied polymer symposium (United States), ITT Rayonier Inc., Shelton, WA 